\title{
Measuring happiness: from fluctuating happiness to authentic-durable happiness
}

\section{Michaël Dambrun 1 *, Matthieu Ricard ${ }^{2,3}$, Gérard Després ${ }^{1}$, Emilie Drelon ${ }^{1}$, Eva Gibelin', Marion Gibelin', Mélanie Loubeyre ${ }^{4}$, Delphine Py ${ }^{1}$, Aurore Delpy ${ }^{1}$, Céline Garibbo ${ }^{1}$, Elise Bray ${ }^{1}$, Gérard Lac ${ }^{5}$ and Odile Michaux ${ }^{5}$}

\author{
1 Laboratoire de Psychologie Sociale et Cognitive, CNRS, Clermont Université, Université Blaise Pascal, Clermont-Ferrand, France \\ ${ }^{2}$ Mind and Life Institute, Boulder, USA \\ ${ }^{3}$ Shechen, Kathmandu, Nepal \\ ${ }^{4} \mathrm{CHU}$, Clermont-Ferrand et Thiers, Université Blaise Pascal, Clermont-Ferrand, France \\ ${ }^{5}$ Laboratoire de Biologie des Activités Physiques et Sportives, Clermont Université, Université Blaise Pascal, Clermont-Ferrand, France
}

Edited by:

Colin G. DeYoung, University of Minnesota, USA

\section{Reviewed by:}

John Zelenski, Carleton University,

Canada

Erik E. Noftle, Willamette University, USA

\section{*Correspondence:}

Michaël Dambrun, Department of

Psychology, Laboratoire de

Psychologie Sociale et Cognitive,

CNRS, Clermont Université,

Université Blaise Pascal, 34 avenue

Carnot, Clermont-Ferrand 63037,

France.

e-mail:michael.dambrun@

univ-bpclermont.fr
On the basis of the theoretical distinction between self-centeredness and selflessness (Dambrun and Ricard, 2011), the main goal of this research was to develop two new scales assessing distinct dimensions of happiness. By trying to maximize pleasures and to avoid displeasures, we propose that a self-centered functioning induces a fluctuating happiness in which phases of pleasure and displeasure alternate repeatedly (i.e., Fluctuating Happiness). In contrast, a selfless psychological functioning postulates the existence of a state of durable plenitude that is less dependent upon circumstances but rather is related to a person's inner resources and abilities to deal with whatever comes his way in life (i.e., Authentic-Durable Happiness). Using various samples ( $n=735)$, we developed a 10-item Scale measuring Subjective Fluctuating Happiness (SFHS) and a 13item scale assessing Subjective Authentic-Durable Happiness (SA-DHS). Results indicated high internal consistencies, satisfactory test-retest validities, and adequate convergent and discriminant validities with various constructs including a biological marker of stress (salivary cortisol). Consistent with our theoretical framework, while self-enhancement values were related only to fluctuating happiness, self-transcendence values were related only to authentic-durable happiness. Support for the distinction between contentment and inner-peace, two related markers of authentic happiness, also was found.

Keywords: happiness, fluctuating happiness, authentic-durable happiness

\section{INTRODUCTION}

Since the early 1990s, researchers in the movement of positive psychology have encouraged the study of the conditions and processes which contribute to the optimal functioning of individuals, groups, and institutions (Seligman and Csikszentmihalyi, 2000; Gable and Haidt, 2005). In recent years, the study of wellbeing and happiness has gradually become a field of primary importance (e.g., Diener, 2000; Csikszentmihalyi and Hunter, 2003; Lyubomirsky et al., 2005). In order to study happiness a valid measuring instrument is needed (Layard, 2010). The first aim of the studies presented in this paper is the development of two such scales: the Subjective Fluctuating Happiness Scale (SFHS) and the Subjective Authentic-Durable Happiness Scale (SA-DHS). The development of these two scales is intimately linked to a recent theoretical model: the Self-centeredness/Selflessness Happiness Model (SSHM; Dambrun and Ricard, 2011). Under this perspective, our second objective is to empirically test the validity of some hypotheses derived from this model.

According to this recent theoretical model, the attainment of happiness is linked to the self, and more particularly to the structure of the self. This model proposes that the perception of a self as a permanent, independent, and solid entity leads to a self-centered psychological functioning that favors a fluctuating happiness. A selfless psychological functioning emerges when the perception of the self is flexible, strongly connected with the environment including others, favoring an authentic and durable happiness.

According to the SSHM (Dambrun and Ricard, 2011), the perception of the self as a real entity with sharp boundaries underlies a self-centered functioning. Laborit (1979) proposes that each entity (or organized structure in the form of an entity), which aims at its preservation, is led to favor gratifications that positively reinforce it, and to avoid disagreeable things that threaten its homeostasis. A self-centered functioning and the exaggerated importance given to the self which comes out of it, leads to a "hedonic principle" (e.g., Higgins, 1997). In this principle, individuals are motivated to obtain pleasure (i.e., approach) and to avoid displeasure (i.e., avoidance). Attaining these objectives (i.e., obtaining gratification and avoiding disagreeable stimuli) creates a feeling of pleasure, joy, and transitory satisfaction. However, these stimulus-driven pleasures are contingent upon the appearance or disappearance of certain stimuli (Wallace and Shapiro, 2006). The experience of pleasure is by nature fleeting and dependent upon circumstances. It is unstable and the sensations it evokes soon becomes neutral (i.e., hedonic adaptation; e.g., Brickman et al., 1978). In addition, the impossibility to attaining valued objectives gives rise to afflictive affects such as frustration, anger, hostility, or 
jealousy that damage well-being (e.g., Miller et al., 1996). Thus, by trying to maximize pleasures and avoiding displeasures, selfcenteredness induces a fluctuating happiness in which phases of pleasure and displeasure alternate repeatedly. Happiness can thus be, at least partly, characterized by the alternation of positive and negative phases that provoke fluctuating happiness. Using the experience sampling method, the work done by Csikszentmihalyi and Hunter (2003) provides a support for the existence of fluctuating happiness. For example, momentary-level scores show that reported happiness varies significantly both with the time of day and day of week. While particular activities significantly increase happiness (e.g., talking with friends), others are associated with a decrease in happiness (e.g., homework and professional work), with the result being that there are important fluctuations in happiness over the course of a day or week. Because the experience sampling method is very demanding, a scale that assesses perceived fluctuating degrees of happiness would be useful. Second, while the experience sampling method assesses "experienced wellbeing," traditional scales measure "evaluated well-being." Each of these two interdependent components has potentials meaningful antecedents and consequences (see Kahneman and Riis, 2005). Thus, a scale measuring evaluated fluctuating happiness would be both valuable and useful. To our knowledge, such a scale does not exist. Thus the first objective of our research was to develop a valid instrument which would reflect perceived degrees of variation in happiness (i.e., the SFHS). Such a measure would contribute to our understanding of happiness and, more particularly, would permit to examine the validity of the SSHM using a questionnaire based correlational study. On the basis of the SSHM, we predict that subjective fluctuating happiness would be robustly and positively related to self-centered values such as Schwartz' self-enhancement values (i.e., achievement and success; e.g., Schwartz, 1992, 2003).

Some theorists propose the existence of a more durable and authentic happiness characterized by meaning and engagement (e.g., Seligman et al., 2005), both intrinsic and pro-social values (e.g., Ryan and Deci, 2001; Lyubomirsky et al., 2005), the development of character strengths such as gratitude (e.g., Peterson and Seligman, 2004), wisdom (e.g., Le, 2011), or selflessness (Dambrun and Ricard, 2011). However, all these characteristics are both antecedents and consequences of authentic-durable happiness rather than markers of it. Authentic happiness is understood here as an optimal way of being, a state of durable contentment and plenitude or inner-peace (based on a quality of consciousness which underlies and imbues each experience, emotion, and behavior, and allows us to embrace all the joys and the pain with which we are confronted). The SSHM (Dambrun and Ricard, 2011) proposes that authentic-durable happiness is intimately linked to selflessness, a psychological functioning characterized by benevolent affects (e.g., compassion, empathy). These affects enhance emotional stability and generate a feeling of being in harmony that favors for example the experience of durable innerpeace and serenity, some markers of authentic-durable happiness. First, while contentment has been the focus of much research (e.g., Diener et al., 1985; Lyubomirsky and Lepper, 1999), plenitude or inner-peace has rarely been taken into account. Thus, in order to assess authentic happiness, it seems relevant and important to take into account these two complementary dimensions. Second, authentic happiness would be a lasting state that could be maintained through the various upheavals of life. Some recent researches support the sustainable happiness model of Lyubomirsky et al. (2005). This model proposes that lasting gains in happiness can occur under specific optimal circumstances. For example, using a longitudinal design, Sheldon et al. (2010) reveal that sustained gains in happiness were observed in three treatment conditions (autonomy vs. competence vs. relatedness), only when there was continuing goal engagement. Thus, the "durable" dimension would also be an important marker of authentic happiness. In other words, a measure of authentic-durable happiness would consist of two related constructs, namely durable contentment and durable inner-peace or plenitude. To our knowledge, existing scales of happiness do not directly assess these dimensions. Many scales assessing happiness and well-being have been developed (e.g., Gurin et al., 1960; Cantril, 1965; Bradburn, 1969; Tellegen, 1982; Dupuy, 1984; Diener et al., 1985; Watson et al., 1988; Argyle et al., 1989; Lyubomirsky and Lepper, 1999; Hills and Argyle, 2002), but none of them seem to focus on the authentic-durable happiness that is characterized by both durable contentment and durable inner-peace. Thus, one of the objectives of the present study was to develop a valid instrument which would assess subjective authentic-durable happiness (i.e., SA-DHS). Such a measure would permit to test one of the hypotheses derived from the SSHM. Specifically, on the basis of this model, we predict that subjective authentic-durable happiness would be robustly and positively related to selfless values such as Schwartz' self-transcendence values (i.e., benevolence and universalism; e.g., Schwartz, 1992, 2003).

In sum, this paper describes two new instruments assessing distinct components of happiness (i.e., the SFHS and the SADHS), and presents studies examining their reliability and validity using various psychological and biological constructs. Data are presented on factorial structure, internal consistency, testretest reliability, convergent and discriminant validity. Moreover, on the basis of the SSHM (Dambrun and Ricard, 2011) and using the Portrait Values Questionnaire (PVQ; Schwartz, 2003), we predict that while subjective fluctuating happiness would be robustly and positively related to self-enhancement values (i.e., self-centeredness), subjective authentic-durable happiness would be robustly and positively related to self-transcendence values (i.e., selflessness).

\section{MATERIALS AND METHODS SCALE DEVELOPMENT}

The 10-item SFHS was created in two steps. First, five items were administered to a university student sample $(n=320)$ in a pilot study. Because reliability of this scale was only moderate $(\alpha=0.70)$, we incorporated five additional items resulting in a 10 -item scale. This last version provides adequate psychometric validity (i.e., high Cronbach alpha and a single factor solution, see below). A single composite score of subjective fluctuating happiness is computed by averaging responses to the 10 items. Thus the possible range of scores is from 1.0 to 7.0 , with higher scores reflecting greater fluctuating happiness. Both French and English versions of this scale are presented in Table 1. Items were introduced by the following: "Below is a collection of statements. Using the 1-7 scale below, please read each statement carefully and then indicate how much you agree or disagree by circling the 
Table 1 | Factor loadings, means, SDs, and item-total correlations.

\begin{tabular}{lllllllllllll}
\hline Scale item & F1 & F2 & F3 & $M$ & SD & IT
\end{tabular}

\section{SUBJECTIVE FLUCTUATING HAPPINESS SCALE (SFHS)}

In my life...2

Dans ma vie...

1. I have had satisfactions and also great disappointments

0.52

je connais des satisfactions, mais également des insatisfactions importantes

2. The periods of pleasure that I have known are always followed by periods of displeasure les phases de plaisir que je connais laissent toujours place à des phases de déplaisir

3. My level of serenity is very changeable

mon niveau de sérénité est très variable

4. I have often known periods of euphoria but they are almost always followed by much less exciting periods

je connais souvent des phases d'euphorie, mais qui laissent presque toujours place à des phases beaucoup moins exaltantes

5. I often go from euphoria to sadness.

je passe souvent de l'euphorie à la tristesse

6. Periods of ill-being follow periods of well-being

à des phases de bien-être succèdent des phases de mal-être

7. My level of happiness is rather unstable, sometimes high, sometimes low

mon niveau de bonheur est plutôt instable, tantôt élevé, tantôt bas

8. I often go from a rather high level of pleasure to a rather low level of pleasure

je passe souvent d'un niveau de plaisir assez élevé à un niveau de plaisir assez faible

9. I have times when I swing from moments of total bliss to much less satisfying moments

je connais des alternances entre des moments de plénitude totale et des moments

beaucoup moins satisfaisants

10. In the same day, I can sometimes be happy and sometimes sad

0.67

0.59

0.75

0.73

0.73

0.72

dans la même journée, il peut m'arriver d'être tantôt joyeux, tantôt malheureux

Full scale

\section{SUBJECTIVE AUTHENTIC-DURABLE HAPPINESS SCALE (SA-DHS)}

In your life ${ }^{2}$, what is your regular ${ }^{1}$ level of. . .

Dans votre vie, quel est votre niveau regulier de...
1. Overall well-being? bien-être general

2. Happiness? bonheur

3. Pleasure? plaisir

4. Bliss (seemingly complete happiness)? félicité (bonheur qui paraît complet)

5. Peace of mind? quiétude (tranquillité d'esprit)

6. Satisfaction? satisfaction

7. Serenity? sérénité

8. Displeasure? déplaisir

9. Beatitude (perfect happiness)? béatitude (bonheur parfait)

10. Inner-peace? paix intérieure

11. Fulfillment? épanouissement

12. Joy? Joie

13. Feeling bad Mal-être

14. Tranquility (inner-calm)? Calme intérieur

15. Plenitude (feeling of complete satisfaction, happiness and fulfillment)? Plénitude

(sentiment d'entière satisfaction, de bonheur et d'épanouissement complets)

16. Unhappiness? Malheur

Full scale

\begin{tabular}{|c|c|c|c|c|}
\hline 0.70 & & 4.72 & 1.17 & 0.73 \\
\hline 0.83 & & 4.91 & 1.23 & 0.74 \\
\hline 0.83 & & 4.79 & 1.18 & 0.70 \\
\hline 0.69 & & 4.02 & 1.47 & 0.73 \\
\hline & 0.67 & 3.97 & 1.52 & 0.68 \\
\hline 0.59 & & 4.52 & 1.20 & 0.68 \\
\hline & 0.69 & 4.37 & 1.34 & 0.68 \\
\hline 0.56 & & 3.37 & 1.53 & 0.68 \\
\hline & 0.74 & 3.90 & 1.59 & 0.67 \\
\hline 0.64 & & 4.52 & 1.30 & 0.68 \\
\hline 0.75 & & 4.82 & 1.18 & 0.66 \\
\hline & 0.75 & 4.11 & 1.44 & 0.67 \\
\hline & 0.66 & 4.03 & 1.36 & 0.74 \\
\hline & & 4.31 & 1.01 & \\
\hline
\end{tabular}

See text footnote 1

${ }^{2}$ See text footnote 2

number which best corresponds to what you think." The accompanying seven-point scale was ranged from 1 (strongly disagree) to 7 (strongly agree).
The 13-item SA-DHS was derived from an original pool of 17 self-report items. These items were incorporated in the pilot study. From these original items, five were dropped because they 
assessed various irrelevant dimensions (e.g., euphoria, frustration). Then, four new items were added to the previous scale. Specifically, in order to control for a compliance bias, two negatively valenced items were added (i.e., displeasure and unhappiness). Finally, two other items assessing inner-peace were added (i.e., inner-peace and plenitude). The final version comprised 16 items with 13 items assessing authentic-durable happiness and three assessing durable unhappiness. Because, we were only interested in assessing happiness (i.e., the positive dimension), the three negatively valenced items were only used to control for the compliance bias. Thus, they were not incorporated into the mean score of happiness. A single composite score for subjective authentic-durable happiness was computed by averaging responses to the 13 positively valenced items. Thus the possible range of scores was from 1.0 to 7.0 , with higher scores reflecting greater authentic-durable happiness. Two sub-scores were calculated by averaging items assessing the contentment component (i.e., overall well-being, happiness, pleasure, bliss, satisfaction, beatitude, fulfillment, and joy) and the inner-peace dimension (i.e., peace of mind, serenity, inner-peace, inner-calm/tranquility, and plenitude). This scale is presented in Table 1. Items were introduced by the following: "Using the 1-7 scale below, please indicate what is your regular ${ }^{1}$ level of happiness in your life ${ }^{2}$." The accompanying seven-point scale was ranged from 1 (very low) to 7 (very high).

\footnotetext{
${ }^{1}$ It is possible to enhance the lasting dimension of authentic happiness by using the word "permanent" instead of the word "regular." This modification does not change the psychometric properties of the scale.

${ }^{2}$ It is possible to impose a recent time frame (e.g., within the past year or within the past few months) to create a more uniform frame of reference.
}

\section{SAMPLES}

The assessment of reliability and validity of the two scales of happiness were obtained through six samples, collected at different times and locations (see Table 2). The temporal stability of the scales was examined using sample A over a 3-month period. The first sample (i.e., sample A) was realized in 2004. The last sample was realized in 2010 (i.e., sample F). The total number of participants was 735. Unlike many studies in personality and social psychology, we did not rely exclusively on university students for our samples (see Sears, 1986). In fact, four of our six samples were composed exclusively of adults from the regional community (one sample was mixed). They were adequately heterogeneous in age, gender, education, religiosity, and SES. All the samples were from France. Table 2 describes each of the samples, and the means, SDs, and alpha reliabilities of the two scales. A formal ethical review of this study was not sought as this study was non-experimental in nature and was a voluntary, confidential (sample A), or anonymous (samples B-F) survey of consenting adults. Verbal informed consent was obtained from all respondents. Thus data were collected and analyzed anonymously or confidentially. All ethical concerns of the Helsinki declaration were followed.

\section{MATERIALS}

First, three measures of happiness and well-being were used to validate the two scales of happiness. The Satisfaction with Life Scale (SLF; Diener et al., 1985), the Positive Affectivity and Negative Affectivity Scale (PANAS; Watson et al., 1988), and a selection of eight items from the Oxford Happiness Questionnaire (OHQ) closely related to happiness and life satisfaction (Hills and Argyle, 2002; e.g., "I do not have particularly happy memories of the past," "I am well satisfied about everything in my life"). Second,

Table 2 | Sample characteristics.

Characteristics

Samples

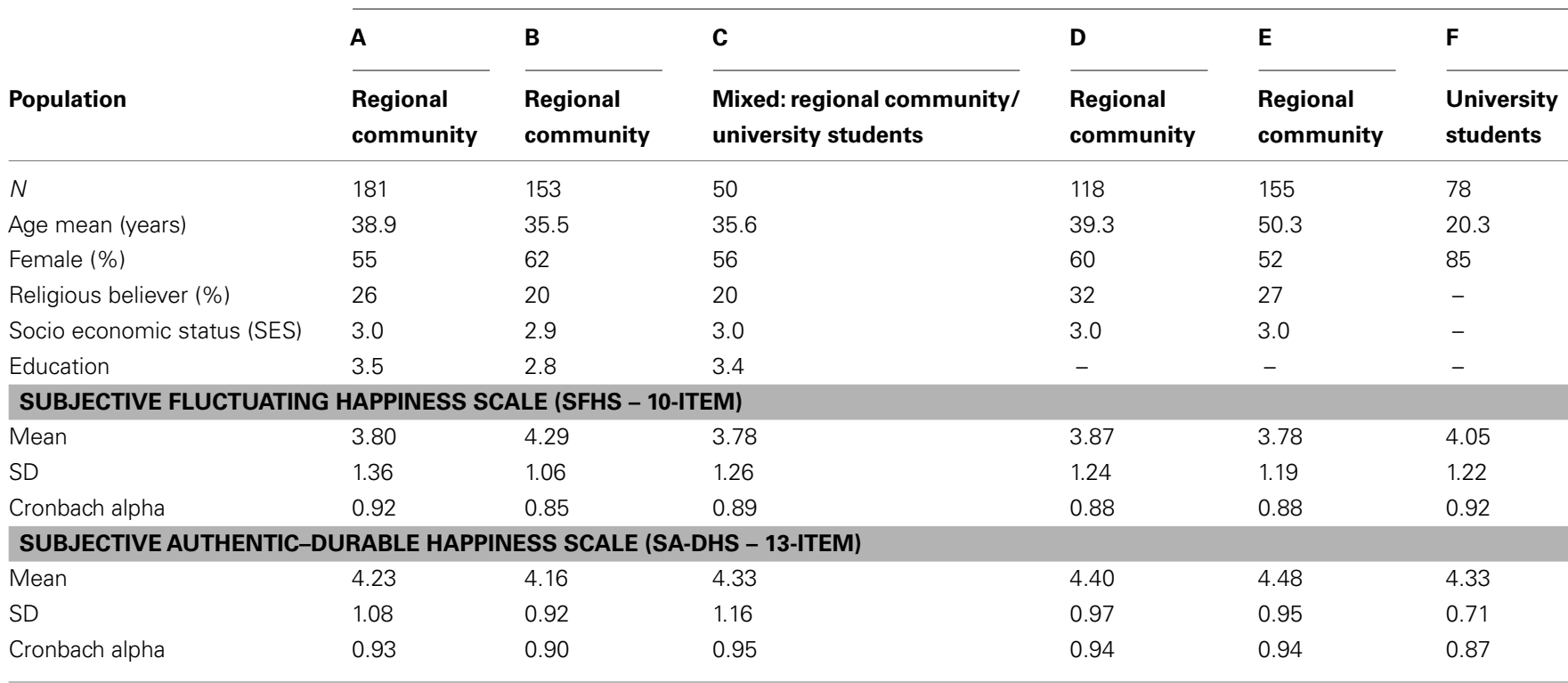

SES was coded from 1 (extremely low SES) to 5 (extremely high SES). Similarly, education was coded from 1 (extremely low education) to 5 (extremely high education). Level of education was not measured in samples D and E. Only age and sex were assessed in sample $F$. 
two measures of mental health were used: the Beck Depression Inventory (BDI; Beck et al., 1988) and the scale of psychological distress (Dambrun, 2007). In order to examine convergent validity, several constructs were measured: (1) dispositional optimism (LOT-R; Scheier et al., 1994); (2) self-efficacy (Jerusalem and Schwarzer, 1992); (3) the sense of coherence with the Sense of Coherence Questionnaire (SCQ; Antonovsky, 1987); (4) perceived resiliency (Dambrun, 2009) ${ }^{3}$; (5) mindfulness with the Mindful Attention Awareness Scale (MAAS; Brown and Ryan, 2003); (6) mental rumination (Trapnell and Campbell, 1999); (7) presence of and search for meaning in life with the Meaning in Life Questionnaire (MLQ; Steger et al., 2006); and (8) salivary cortisol $^{4}$ (a biological marker of stress; sample F). To the extent that several markers of happiness such as positive affects (Steptoe and Wardle, 2005; Steptoe et al., 2005) and some dimensions of psychological well-being (Ryff et al., 2006) were found to correlate negatively and significantly with salivary cortisol, we predict that our measure of authentic-durable happiness would be negatively and significantly related to the level of salivary cortisol. Finally, in order to examine the validity of some of the hypotheses derived from the Selfcentered/Selflessness Happiness Model, self-enhancement (i.e., achievement, power), and self-transcendence (i.e., benevolence, universalism) values were measured (PVQ; Schwartz, 2003).

\section{RESULTS AND DISCUSSION \\ EXPLORATORY FACTOR ANALYSES}

To explore the factor structure of the two scales, we used the first five samples, resulting in a pool of 657 Adults French Citizens (see Table 2). Because sample F was exclusively composed of psychology students, it was not included in the factor analyses.

\section{THE SUBJECTIVE FLUCTUATING HAPPINESS SCALE}

The principal component factor analysis with varimax rotation of the 10 items revealed a single factor solution. The Kaiser measure of sampling adequacy was 0.91 . The single factor accounted for $50.53 \%$ of the total variance (Eigenvalue $=5.05$ ). All items loaded appropriately on a single factor (factor loadings ranged from 0.53 to 0.80$)$.

\section{THE SUBJECTIVE AUTHENTIC-DURABLE HAPPINESS SCALE}

The principal component factor analysis with varimax rotation of the 13 items disclosed two factors with Eigenvalues greater than 1. The Kaiser measure of sampling adequacy was 0.93 . The first factor accounted for $56 \%$ of the explained variance and regrouped eight items assessing the contentment dimension of happiness

\footnotetext{
${ }^{3}$ This scale included six-items which assessed perceived resiliency (e.g., "When something unpleasant happens to me I get over it fairly quickly"). This scale has a satisfactory reliability $(\alpha=0.83)$, adequate construct validity, and has a single factor structure.

${ }^{4}$ Cortisol was assayed by ELISA using commercial kits (AbCys SA, Paris, France), according to the manufacturer's recommendations (including sampling steps) allowing the best performances of coefficient of variation $(\mathrm{CV})$ and sensitivity. Sensitivity, intra- and interassay CVs were $0.05 \mathrm{ng} / \mathrm{ml}, 7$ and $9.3 \%$. Because salivary cortisol varies greatly during the day, one strategy consists to measure salivary cortisol repeatedly. Another possibility is to measure salivary cortisol at times when it does not vary or low (between 10am and 12am in the morning and between 16:30 and 19:30 in the afternoon; e.g., Lac and Chamoux, 2000). For constraints reasons, we opted for the latter.
}

(i.e., overall well-being, happiness, pleasure, bliss, satisfaction, beatitude, fulfillment, and joy; Eigenvalue $=7.25$; factor loadings ranged from 0.58 to 0.85 ). The second factor accounted for $8.57 \%$ of the explained variance and regrouped five items assessing the inner-peace component of happiness (i.e., peace of mind, serenity, inner-peace, inner-calm, plenitude; Eigenvalue $=1.11$; factor loadings ranged from 0.52 to 0.80 ).

\section{ARE SUBJECTIVE FLUCTUATING HAPPINESS AND AUTHENTIC-DURABLE HAPPINESS DISTINCT CONSTRUCTS?}

To answer this question, we performed a new Factor Analysis with all items from the two scales. The Kaiser measure of sampling adequacy was 0.94 . This analysis disclosed three factors with Eigenvalues greater than 1 . The first factor accounted for $40.8 \%$ of the explained variance and regrouped all items assessing subjective fluctuating happiness. The second factor accounted for $13.05 \%$ of the explained variance and regrouped items assessing durable contentment. Finally, the third factor accounted for $5.22 \%$ of the explained variance and regrouped items assessing durable inner-peace. Thus, fluctuating happiness and authentic-durable happiness are two distinct constructs. The inter-correlation between these two scales is -0.48 . In other words, these scales share $23 \%$ of the variance. Finally, the inter-correlation between the two factors of authentic-durable happiness (i.e., contentment and inner-peace) is 74 , thus they share $55 \%$ of the variance. A confirmatory factor analysis (CFA) revealed the same basic findings ${ }^{5}$.

\section{INTERNAL CONSISTENCY OF THE SCALES}

The internal consistency of the two scales was examined using all samples. For the SFHS, Cronbach alpha was equal to 0.89. Concerning the SA-DHS, the Cronbach alpha was 0.93 . We also examined the internal consistency of the sub-dimensions of this scale. Both the contentment sub-scale $(\alpha=0.90)$ and the inner-peace sub-scale ( $\alpha=0.87$ ) had satisfactory internal consistencies.

\section{TEST-RETEST RELIABILITY AND AGREEMENT}

The temporal stability of the scales was examined using sample A over a 3-month period. Both subjective authentic-durable happiness scores $(r=0.90, p<0.001)$ and subjective fluctuating happiness scores $(r=0.85, p<0.001)$ were highly correlated between time 1 and time 2 ( 3 months later). Another index of stability is test-retest score agreement, that is, individuals generally receive the same scale scores over repeated assessment (Dawis, 2000). Scores on the SA-DHS were not significantly different between time $1\left(M_{1}=4.25, \mathrm{SD}=1.09\right)$ and time $2\left[M_{2}=4.21\right.$, $\mathrm{SD}=1.10 ; t(171)<1]$. Similarly, scores on the SFHS were similar in time $1\left(M_{1}=3.80, \mathrm{SD}=1.37\right)$ and time $2\left[M_{2}=3.79\right.$, $\mathrm{SD}=1.27 ; t(171)<1]$.

\footnotetext{
${ }^{5}$ A series of confirmatory factor analyses revealed that the predicted model with three latent variables [i.e., (1) items assessing fluctuating happiness and authenticdurable happiness decomposed in (2) items assessing durable contentment and (3) items assessing durable inner-peace] provided a better description of the data $\left[\chi^{2}(223)=1051, p<0.001 ; \mathrm{NFI}=0.89 ; \mathrm{CFI}=0.91\right.$; RMSA $\left.=0.07\right]$ than models with two latent variables or a single latent variable [respectively, $\chi^{2}(227)=1324$, $p<0.001 ; \mathrm{NFI}=0.85 ; \mathrm{CFI}=0.86$; RMSEA $=0.09$, and $\chi^{2}(229)=3538, p<0.001$; $\mathrm{NFI}=0.60 ; \mathrm{CFI}=0.62 ; \mathrm{RMSEA}=0.15]$.
} 


\section{CONVERGENT VALIDITY WITH MEASURES OF WELL-BEING AND MENTAL HEALTH}

In order to assess convergent validity, we examined the correlations between our two scales and published measures of happiness, well-being, and mental health. This analysis was performed using samples A, B, C, and D. Table 3 presents the main findings, which show substantial correlations between the main measures (i.e., subjective well-being, OHQ, depression, and psychological distress) and the SA-DHS ( $r$ ranged from 0.48 to $0.71 ; M=0.60$ ) and moderate correlations in the case of the SFHS ( $r$ ranged from 0.24 to $0.48 ; M=0.38$ ).

We also performed partial correlations, in which, first, the relationships between SA-DHS and the various dependent variables was controlled for fluctuating happiness, and second, the relationships between, SFHS and the various dependent variables was controlled for authentic-durable happiness. While positive affectivity was robustly related to the SA-DHS (partial $r$ ranged from 0.32 to 0.38 ), negative affectivity was more robustly related to the SFHS (partial $r$ ranged from 0.51 to 0.55 ). As for positive affectivity, life satisfaction was more robustly related to the SA-DHS than to the SFHS. However, both scales correlated significantly with subjective well-being; negatively for the SFHS (partial $r$ ranged from -0.24 to -0.44 ), and positively for the SA-DHS (partial $r$ ranged from 0.56 to 0.66 ). Items selected from the $\mathrm{OHQ}$ correlated appropriately with the two scales. Finally, both measures of mental health (i.e., depression and psychological distress) correlated significantly and positively with the SFHS (partial $r$ ranged from 0.36 to 0.48 ) and negatively with the SA-DHS (partial $r$ ranged from -0.36 to -0.43$)$.

\section{CONVERGENT VALIDITY WITH RELEVANT PSYCHOLOGICAL CONSTRUCTS}

We also assessed convergent validity using a number of psychological constructs with which happiness has been theoretically and empirically associated in previous research, namely optimism (Scheier and Carver, 1985; Seligman, 1991), self-efficacy (Bandura, 1991), a sense of coherence (Antonovsky, 1987), resiliency (Rutter, 1985; Werner, 1992), mindfulness (Brown and Ryan, 2003), mental rumination (Trapnell and Campbell, 1999), and presence of and search for meaning in life (Steger et al., 2006). The main results are presented in Table 4. Correlations with relevant constructs were moderate, ranging from 0.22 to 0.53 for the SA-DHS $(M=0.37)$ and from 0.25 to 0.53 . $(M=0.39)$ for the SFHS.

Again, we calculated partial correlations. The results showed that SA-DHS is robustly and positively related to optimism, selfefficacy, a sense of coherence, perceived resiliency, and the presence of meaning in life. Thus, those who perceived themselves as experiencing authentic-durable happiness, were optimistic, perceived themselves as effective, resilient, having a sense of coherence, and indicated the presence of meaning in their life. Subjective fluctuating happiness was robustly and positively correlated to mental rumination and the search for meaning in life. Thus, those who experienced fluctuating happiness were those who ruminated and searched for meaning in their life. Similarly, those who perceived themselves as optimistic, coherent, resilient, mindful, and having a presence of meaning in their life reported significantly less fluctuating happiness. It is worth noting that while self-efficacy is robustly related only to authentic-durable happiness, both mental rumination and mindlessness are robustly correlated only with fluctuating happiness. Thus, both the absence of mental rumination and mindfulness are not robust predictors of authenticdurable happiness, they are only related to a decrease in terms of fluctuation in happiness.

\section{SELF-ENHANCEMENT AND SELF-TRANSCENDENCE VALUES AND HAPPINESS}

Correlations between values and happiness measures are presented in Table 4. As predicted on the basis of the SSHM,

Table 3 | Correlations of the Subjective Authentic-Durable Happiness Scale and the Subjective Fluctuating Happiness Scale with various measures of well-being, happiness, and mental health.

\begin{tabular}{|c|c|c|c|c|c|}
\hline \multirow[t]{2}{*}{ Scales } & \multirow[t]{2}{*}{ Sample(s) } & \multicolumn{2}{|c|}{ SA-DHS } & \multicolumn{2}{|c|}{ SFHS } \\
\hline & & $r$ & Partial $r$ & $r$ & Partial $r$ \\
\hline Positive affectivity & $\mathrm{D}$ & $0.35^{* * *}$ & $0.32 * * *$ & $-0.17^{\dagger}$ & -0.05 \\
\hline \multirow[t]{2}{*}{ Negative affectivity } & A & $-0.31 * * *$ & -0.06 & $0.51 * * *$ & $0.49 * * *$ \\
\hline & $\mathrm{D}$ & $-0.33^{* * *}$ & $-0.17^{\dagger}$ & $0.55^{* * *}$ & $0.49 * * *$ \\
\hline \multirow{3}{*}{ Life satisfaction } & $\mathrm{B}$ & $0.64 * *$ & $0.43^{* * *}$ & $-0.62 * * *$ & $-0.40 * * *$ \\
\hline & $\mathrm{C}$ & $0.61 * * *$ & $0.45^{* * *}$ & $-0.48^{* * *}$ & -0.12 \\
\hline & $\mathrm{D}$ & $0.67 * * *$ & $0.61 * * *$ & $-0.38 * * *$ & $-0.20^{*}$ \\
\hline \multirow[t]{2}{*}{ Subjective well-being $(S W B)^{\ddagger}$} & A & $0.68 * * *$ & $0.56 * * *$ & $-0.53 * * *$ & $-0.24 * * *$ \\
\hline & $\mathrm{D}$ & $0.71 * * *$ & $0.66^{* * *}$ & $-0.54 * * *$ & $-0.44 * * *$ \\
\hline Oxford Happiness Questionnaire (OHQ) & $\mathrm{B}$ & $0.59 * * *$ & $0.39 * * *$ & $-0.57^{* * *}$ & $-0.35^{* * *}$ \\
\hline
\end{tabular}

${ }^{* *} p<0.001 ;{ }^{*} p<0.01 ;{ }^{*} p<0.05 ;{ }^{\dagger} p<0.10 ;$ SA-DHS, Subjective Authentic-Durable Happiness Scale; SFHS, Subjective Fluctuating Happiness Scale.

${ }^{\ddagger}$ The measure of Subjective Well-Being (SWB) is constituted by the presence of positive affectivity, the absence of negative affectivity, and the presence of life satisfaction (Diener, 1984). 
Table 4 | Correlations of the Subjective Authentic-Durable Happiness Scale and the Subjective Fluctuating Happiness Scale with various convergent measures (samples $D$ and $E$ ).

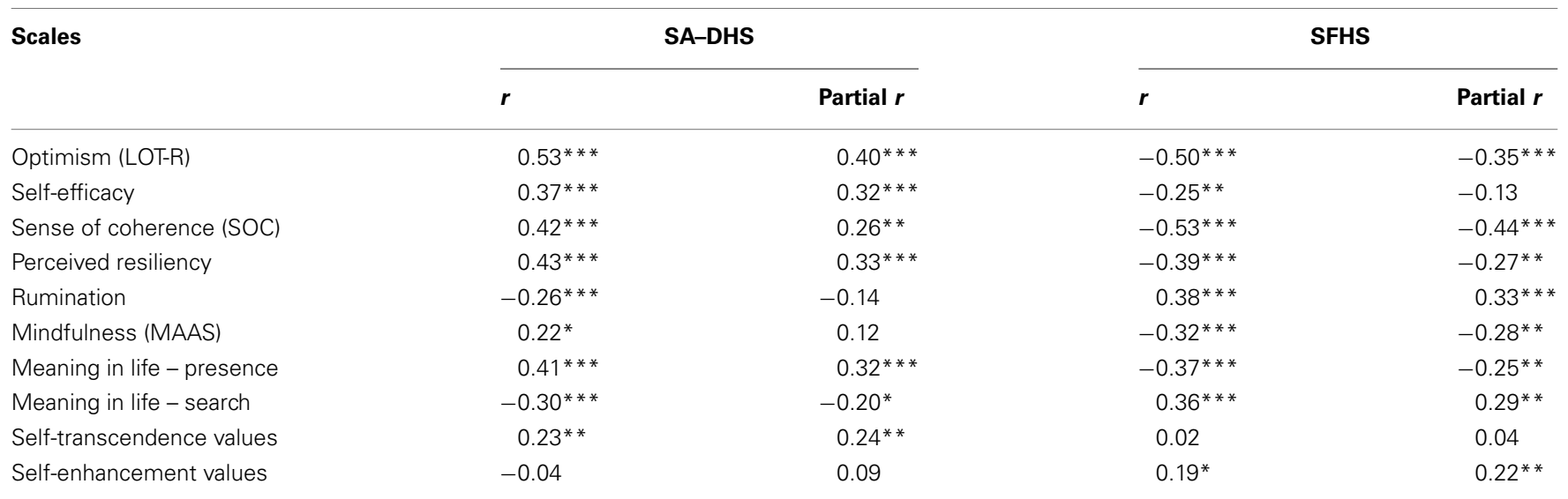

${ }^{* *} p<0.001 ;{ }^{*} p<0.01 ;{ }^{*} p<0.05 ; p<0.10 ;$ SA-DHS, Subjective Authentic-Durable Happiness Scale; SFHS, Subjective Fluctuating Happiness Scale. Selftranscendence values comprise benevolence and universalism. Power and achievement compose self-enhancement values.

self-enhancement values (i.e., achievement and power) were positively and significantly related to subjective fluctuating happiness, but not to subjective authentic-durable happiness. The exact opposite was found for self-transcendence values (i.e., benevolence and universalism); they were positively and significantly related to authentic-durable happiness, but not to subjective fluctuating happiness.

\section{CONVERGENT VALIDITY WITH SALIVARY CORTISOL}

We also assessed convergent validity using a biological marker with which well-being has been empirically associated in previous research, namely salivary cortisol (e.g., Steptoe et al., 2005; Ryff et al., 2006). The main results are presented in Table 5. Interestingly, the only scale that was significantly related to this hormone stress was the SA-DHS $(r=-0.22, p<0.05)$. The life satisfaction scale, the measure of subjective well-being, and the SFHS were not significantly related to this biological marker.

\section{DISCRIMINANT VALIDITY}

In order to provide an additional test for the robustness of our two new scales, we performed some discriminant analyses. According to Veenhoven (1997), in Western countries such as France, constructs that should not be related to happiness include age and education. Thus, we computed the correlations between these variables and our two measures of happiness across the samples. As expected, age was neither correlated with the SFHS $(r=-0.05, p>0.10)$, nor to the SA-DHS $(r=0.04$, $p>0.10)$. Similarly, the SFHS $(r=0.03, p>0.10)$ and the SADHS ( $r=-0.07, p>0.10$ ) were not significantly related to education. Furthermore, we did not find support for gender differences. Social status showed only a marginal effect which is consistent with previous studies (see Veenhoven, 1997); people in advantaged social positions experienced marginally more authentic-durable happiness $(r=0.07, p<0.09)$ and marginally less fluctuating happiness $(r=-0.07, p<0.08)$. Finally, there were no significant differences between atheists and religious believers.
Table 5 | Correlations between salivary cortisol and happiness and well-being measures (Sample F).

\begin{tabular}{lll}
\hline Scales & \multicolumn{2}{c}{ Salivary cortisol level $(\mathbf{n g} / \mathbf{m l})$} \\
\cline { 2 - 3 } & $\boldsymbol{r}$ & Partial $\boldsymbol{r}$ \\
\hline Life satisfaction & -0.13 & - \\
Subjective well-being & -0.04 & - \\
SFHS & $0.18^{\dagger}$ & 0.09 \\
SA-DHS & $-0.22^{*}$ & - \\
Factor 1: contentment & -0.12 & - \\
Factor 2: inner-peace & $-0.29^{* *}$ & $-0.26^{*}$ \\
\hline
\end{tabular}

${ }^{* *} p<0.01 ;{ }^{*} p<0.05 ;{ }^{+} p<0.10$.

\section{THE TWO COMPONENTS OF SUBJECTIVE AUTHENTIC-DURABLE HAPPINESS: DISTINGUISHING CONTENTMENT AND INNER-PEACE}

After finding support for a two factors solution of the SA-DHS scale, we examined how each component was related to other constructs. First, we studied how the contentment sub-scale and the inner-peace sub-scale correlated with other measures of happiness, well-being and mental health. Second, we examined the relationships between these two dimensions and the relevant psychological and biological constructs. Using samples A to E, it is interesting to note that participants reported a greater level of durable contentment $(M=4.46 ; \mathrm{SD}=1.00)$ than of durable inner-peace $[M=4.07 ; \mathrm{SD}=1.18 ; t(650)=12.38, p<0.001]$.

Table 6 indicates the relationships between the two dimensions of the SA-DHS and the various measures of happiness, well-being, and mental health. The Pearson correlations indicate that the two sub-scales correlate appropriately with the various measures. In a second step, we also computed partial correlations. Interestingly, once durable inner-peace is statistically controlled for, the relationships between durable contentment, subjective wellbeing and the OHQ still remain highly significant. On the other 
hand, when durable contentment is statistically controlled for, the relationships between durable inner-peace and these two measures are strongly reduced. These results suggest that the contentment sub-scale is more closely related to the existing measures of happiness and well-being that the inner-peace sub-scale. We found the exact opposite when we looked at mental health measures. While the relationships between durable contentment, depression, and psychological distress vanish when inner-peace is statistically controlled for, the relationships between inner-peace and mental health measures still remain highly significant when durable contentment is statistically controlled. Thus, durable inner-peace is a more robust predictor of mental health than contentment.
Finally, we explored the relationships between these two subscales and various convergent psychological (see Table 7) and biological (Table 5) constructs. While the Pearson correlations indicate adequate convergent validity, the partial correlations reveal some interesting findings. Concerning psychological constructs, when durable inner-peace is statistically controlled for, only the correlation between durable contentment and optimism (LOT-R) remains significant. All the other relationships become non-significant. On the other hand, when durable contentment is statistically controlled for, most of the relationships between durable inner-peace and the various convergent psychological constructs remain significant or marginally significant. For

Table 6 | Correlations of the two components of Subjective Authentic-Durable Happiness (i.e., contentment and inner-peace) with various measures of well-being, happiness, and mental health.

\begin{tabular}{|c|c|c|c|c|c|}
\hline \multirow[t]{2}{*}{ Scales } & \multirow[t]{2}{*}{ Sample(s) } & \multicolumn{2}{|c|}{ Factor 1: contentment } & \multicolumn{2}{|c|}{ Factor 2: inner-peace } \\
\hline & & $r$ & Partial $r$ & $r$ & Partial $r$ \\
\hline \multirow[t]{2}{*}{ Positive affectivity } & $A$ & $0.43 * * *$ & $0.37 * * *$ & $0.27 * * *$ & -0.09 \\
\hline & $\mathrm{D}$ & $0.34 * * *$ & $0.16^{\dagger}$ & $0.32 * * *$ & 0.10 \\
\hline \multirow[t]{2}{*}{ Negative affectivity } & $A$ & $-0.26^{* * *}$ & 0.01 & $-0.33^{* * *}$ & $-0.25^{* * *}$ \\
\hline & $\mathrm{D}$ & $-0.26^{* * *}$ & 0.03 & $-0.37^{* * *}$ & $-0.27^{* *}$ \\
\hline \multirow[t]{4}{*}{ Life satisfaction } & $A$ & $0.62 * * *$ & $0.46 * * *$ & $0.51 * * *$ & 0.06 \\
\hline & $B$ & $0.67^{* * *}$ & $0.54^{* * *}$ & $0.48 * * *$ & -0.04 \\
\hline & $\mathrm{C}$ & $0.67^{* * *}$ & $0.60 * * *$ & $0.47^{* * *}$ & $0.29 *$ \\
\hline & $\mathrm{D}$ & $0.68 * * *$ & $0.47^{* * *}$ & $0.56 * * *$ & 0.09 \\
\hline \multirow[t]{2}{*}{ Subjective well-being $(S W B)^{\dagger}$} & A & $0.69 * * *$ & $0.52 * * *$ & $0.57^{* * *}$ & $0.13^{\dagger}$ \\
\hline & $\mathrm{D}$ & $0.68 * * *$ & $0.40^{* * *}$ & $0.64^{* * *}$ & $0.25^{* *}$ \\
\hline Oxford Happiness Questionnaire (OHQ) & $B$ & $0.59 * * *$ & $0.39 * * *$ & $0.48 * * *$ & 0.09 \\
\hline Depression (BDI) & $\mathrm{D}$ & $-0.46 * * *$ & -0.12 & $-0.52 * * *$ & $-0.30 * * *$ \\
\hline Psychological distress & $\mathrm{D}$ & $-0.42^{* * *}$ & -0.11 & $-0.48^{* * *}$ & $-0.26^{* * *}$ \\
\hline
\end{tabular}

${ }^{*}{ }^{*} p<0.001 ;{ }^{*} p<0.01 ;{ }^{*} p<0.05 ;{ }^{\dagger} p<0.10 ;$ SA-DHS, Subjective Authentic-Durable Happiness Scale; SFHS, Subjective Fluctuating Happiness Scale.

${ }^{t}$ The measure of Subjective Well-Being (SWB) is constituted by the presence of positive affectivity, the absence of negative affectivity, and the presence of life satisfaction (Diener, 1984).

Table 7 | Correlations of the two components of Subjective Authentic-Durable Happiness (i.e., contentment and inner-peace) with various convergent measures (Samples D and E).

\begin{tabular}{|c|c|c|c|c|}
\hline \multirow[t]{2}{*}{ Scales } & \multicolumn{2}{|c|}{ Factor 1: contentment } & \multicolumn{2}{|c|}{ Factor 2: inner-peace } \\
\hline & $r$ & Partial $r$ & $r$ & Partial $r$ \\
\hline Optimism (LOT-R) & $0.49 * * *$ & $0.24^{*}$ & $0.51 * * *$ & $0.20^{*}$ \\
\hline Self-efficacy & $0.34 * * *$ & 0.12 & $0.35 * * *$ & 0.15 \\
\hline Sense of coherence (SOC) & $0.35^{* * *}$ & 0.07 & $0.43^{* * *}$ & $0.25^{* *}$ \\
\hline Perceived resiliency & $0.36 * * *$ & 0.04 & $0.45 * * *$ & $0.29 * *$ \\
\hline Rumination & $-0.17^{\dagger}$ & 0.10 & $-0.34 * * *$ & $-0.30 * * *$ \\
\hline Mindfulness (MAAS) & $0.17^{\dagger}$ & -0.02 & $0.25 * * *$ & $0.18^{\dagger}$ \\
\hline Meaning in life - presence & $0.38 * * *$ & 0.13 & $0.39 * * *$ & $0.17^{\dagger}$ \\
\hline Meaning in life - search & $-0.22^{*}$ & 0.07 & $-0.37^{* * *}$ & $-0.29 * *$ \\
\hline Self-transcendence values & $0.20 * *$ & 0.08 & $0.22^{* *}$ & 0.17 \\
\hline Self-enhancement values & 0.08 & - & -0.05 & - \\
\hline
\end{tabular}

${ }^{* *} p<0.001 ;{ }^{*} p<0.01 ;{ }^{*} p<0.05 ;{ }^{\dagger} p<0.10$. 
example, only durable inner-peace is robustly related to a sense of coherence, perceived resiliency, rumination, mindfulness, the search for meaning in life, and the presence of meaning in life. Finally, only durable inner-peace is significantly and negatively related to the salivary cortisol level (see Table 5 ). Thus, this relatively unexplored dimension appears to have highly relevant associations.

\section{GENERAL DISCUSSION}

This study provides the first empirical support for the distinction between evaluated fluctuating happiness and evaluated authenticdurable happiness. Despite some limitations, the present study provides some significant advances. We proposed two new instruments - the SFHS and the SA-DHS - that are characterized by high internal consistency, a logical factorial structure, and stability over time. Importantly, and as predicted, items from the SFHS and those of the SA-DHS load on distinct factors, suggesting they are distinct dimensions of happiness. Despite a moderate but significant negative correlation between these two dimensions, fluctuating happiness seems not to be simply the reverse of authentic-durable happiness. Exploration of the scales' construct validity confirms, first, that both scales have adequate convergent construct validity, and, second, using partial correlations, that they assess distinct facets of human happiness. While the SA-DHS was more closely related to positive affectivity and life satisfaction, the SFSH was more closely related to negative affectivity. Thus, fluctuation of happiness, despite the experience of phases of pleasure, seems to be more linked to emotional negativity than to emotional positivity. While both scales were robustly related to optimism, a sense of coherence, perceived resiliency, and the presence of and the search for meaning in life, only the SFHS was robustly related to both mental rumination and mindlessness. Thus both mental rumination and escape from the present moment are involved in fluctuating happiness. Brown and Ryan (2003) found that mindfulness was a robust predictor of well-being. The present results suggest that mindfulness, being able to focus on the present moment and not focus on past or future events, rather than enhancing contentment or happiness, is robustly related to a decrease of alternation between phases of satisfaction and dissatisfaction. These results must be confirmed in future research.

We also found support for a distinction between two markers of authentic happiness, namely durable contentment and durable inner-peace or plenitude. First, factor analyses showed a two factors solution with items assessing contentment loading on the first factor and those assessing inner-peace loading on the second factor. Second, the relevance of this distinction was confirmed by analyses examining the relationships between these two dimensions and both well-being and relevant psychological and biological constructs. As predicted, existing happiness and well-being measures (i.e., SWB, life satisfaction, the OHQ) were strongly and robustly correlated with durable contentment, but not, or not strongly correlated with durable inner-peace. This confirms that contentment is already present in existing scales, but not inner-peace. However, the only robust predictor of mental health and cortisol level was durable inner-peace. This suggests that inner-peace, rather than contentment, could have beneficial consequences in terms of treating stress, depression, and psychological distress. The negative correlation between durable inner-peace and salivary cortisol is consistent with the existing literature (e.g., Steptoe et al., 2005; Ryff et al., 2006). However, it would be important to replicate this result using a multiple measurement of salivary cortisol ${ }^{4}$. Finally, examination of the relationships between the two factors of the SA-DHS and convergent psychological constructs revealed some interesting results. While both components were robustly related to optimism, only durable inner-peace was found to robustly predict the other various constructs such as a sense of coherence, perceived resiliency, mental rumination, mindfulness, and the search for and the presence of meaning in life. These results suggest that the relationships between happiness, life satisfaction and their usual psychological correlates may be due, at least partly, to an unmeasured component, namely durable inner-peace. In order to determine the respective role of contentment and inner-peace in the psychology of human happiness, it is important that future research includes measurement of these two dimensions.

Results of the present study also provide a preliminary support for the SSHM (Dambrun and Ricard, 2011). According to this theoretical framework, while fluctuating happiness would be related to a self-centered functioning, authentic-durable happiness would be related to selflessness. Using the PVQ (Schwartz, 2003), we examined to correlations between self-centered values such as self-enhancement (i.e., achievement, power), selfless values such as self-transcendence (i.e., universalism and benevolence) and the two types of happiness, namely fluctuating and authenticdurable happiness. Consistent with this model, while fluctuating happiness was related only to self-enhancement values, authenticdurable happiness was related only to self-transcendence values. Of course, because our design is correlational, it is impossible to provide strong claims about causality. Future studies using experimental designs would increase our confidence in the causal direction between self-based psychological functioning (i.e., selfcenteredness and selflessness) and happiness (i.e., fluctuating and authentic-durable). Moreover the psychological processes that are theoretically implied in this relation need to be examined. Nonetheless, these results provide a first empirical support for this model.

Finally, this study has some limitations that must be taken into account. First, using the experience sampling method, it would be relevant to reproduce the present findings. According to the SSHM, self-centeredness and selflessness are not only related to distinct patterns of evaluated happiness, but also to distinct pattern of experienced happiness. In addition, the model predicts that self-centeredness and selflessness can be evaluated, but would first experienced. Thus, it would be relevant to examine the hypotheses derived from this model using the experience sampling method. This approach would test our model by minimizing the bias associated with the recovery of memories and those associated with the development of global judgments (e.g., judgments based on the most accessible memories; Kahneman, 1999). In addition, these techniques provide continuous monitoring of longitudinal samples in the short or long term that can permit to infer temporal relationships (e.g., Steger et al., 2008). Second, some cautions need to be taken concerning both the content and the ultimate 
construct validity of our scales. Concerning the content construct validity, the fact that the two types of happiness were measured differently may reduce artificially the correlation between the two constructs and also may favor a separated factor structure. Concerning the ultimate construct validity of the SFHS, more research

\section{REFERENCES}

Antonovsky, A. (1987). Untraveling the Mastery of Health: How People Manage Stress and Stay Well. San Francisco: Jossey-Bass.

Argyle, M., Martin, M., and Crossland, J. (1989). "Happiness as a function of personality and social encounters," in Recent Advances in Social Psychology: An International Perspective, eds J. P. Forgas and J. M. Innes (North-Holland: Elsevier), 189-203.

Bandura, A. (1991). “Self-efficacy mechanism in physiological activation and health promoting behavior," in Adaptation, Learning, and Affect, eds J. I. Madden, S. Matthysee, and J. Barchas (New York: Raven), 229269.

Beck, A. T., Steer, R. A., and Garbin, M. G. (1988). Psychometric properties of the Beck Depression Inventory: twenty-five years of evaluation. Clin. Psychol. Rev. 8, 77-100.

Bradburn, N. M. (1969). The Structure of Psychological Well-Being. Chicago: Alpine.

Brickman, P., Coates, D., and JanoffBulman, R. (1978). Lottery winners and accident victims: is happiness relative? J. Pers. Soc. Psychol. 36, 917-927.

Brown, K. W., and Ryan, R. M. (2003). The benefits of being present: mindfulness and its role in psychological well-being. J. Pers. Soc. Psychol. 84, 822-848.

Cantril, H. (1965). The Pattern of Human Concerns. New Brunswick: Rutgers University Press.

Csikszentmihalyi, M., and Hunter, J. (2003). Happiness in everyday life: the uses of experience sampling. $J$. Happiness Stud. 4, 185-199.

Dambrun, M. (2007). Gender differences in mental health: the mediating role of perceived discrimination. J. Appl. Soc. Psychol. 37, 1118-1129.

Dambrun, M. (2009). A Short Measure of Perceived Resiliency. Unpublished manuscript, Clermont University, UBP, Clermont-Ferrand.

Dambrun, M., and Ricard, M. (2011). Self-centeredness and selflessness: a theory of self-based psychological functioning and its consequences for happiness. Rev. Gen. Psychol. 15, 138-157.
Dawis, R. V. (2000). "Scale construction and psychometric considerations," in Handbook of Applied Multivariate Statistics and Mathematical Modeling, eds H. E. A. Tinsley and S. D. Brown (San Diego, CA: Academic Press), 65-94.

Diener, E. (1984). Subjective well-being. Psychol. Bull. 95, 542-575.

Diener, E. (2000). Subjective well-being: the science of happiness, and a proposal for a national index. Am. Psychol. 55, 34-43.

Diener, E., Emmons, R. A., Larsen, R. J., and Griffin, S. (1985). The satisfaction with life scale. J. Pers. Assess. 49, 71-75.

Dupuy, H. J. (1984). “The psychological general well-being scale," in Assessment of Quality Life in Clinical Trials of Cardiovascular Therapies, ed. $\mathrm{N}$. Wenger (Washington: Le Jacq), 170-199.

Gable, S. L., and Haidt, J. (2005). What (and why) is positive psychology? Rev. Gen. Psychol. 9, 103-110.

Gurin, G., Veroff, J., and Feld, S. (1960). Americans View their Mental Health. New York: Basic Books.

Higgins, E. T. (1997). Beyond pleasure and pain. Am. Psychol. 52, 1280-1300.

Hills, P., and Argyle, M. (2002). The Oxford Happiness Questionnaire: a compact scale for the measurement of psychological well-being. Pers. Individ. Dif. 33, 1073-1082.

Jerusalem, M., and Schwarzer, R. (1992). "Self-efficacy as a resource factor in stress appraisal processes," in Self-Efficacy: Thought Control of Action. eds R. Schwarzer and R. Schwarzer (Washington, DC: Hemisphere Publishing Corp.), 195-213.

Kahneman, D. (1999). "Objective happiness," in Well-Being: The Foundations of Hedonic Psychol$o g y$, eds D. Kahneman, E. Diener, N. Schwarz, D. Kahneman, E. Diener, and N. Schwarz (New York, NY: Russell Sage Foundation), 3-25.

Kahneman, D., and Riis, J. (2005). "Living, and thinking about it: two perspectives on life," in The Science of Well-Being, eds F. A. Huppert, N. Baylis, and B. Keverne (New York, NY: Oxford University Press), 285-304.

is needed. For example, it would be relevant to examine the extent to which SFHS is distinct from a self-report scale of bipolar disorder. Demonstrating that the scales presented in this paper correlate in the expected sense to actual experiential trends in happiness could make a convincing case.

Laborit, H. (1979). L'inhibition de l'action : Biologie, physiologie, psychologie, sociologie. Editions Masson.

Lac, G., and Chamoux, A. (2000). Un référentiel du rythmecircadien du cortisol salivaire chez l'homme au travail (A salivary cortisol circadian rhythm referential in man at work). Arch. Mal. Prof. 61, 469-473.

Layard, R. (2010). Measuring subjective well-being. Science 327, 534-535.

Le, T. N. (2011). Life satisfaction, openness value, self-transcendence, and wisdom. J. Happiness Stud. 12, 171182.

Lyubomirsky, S., and Lepper, H. S. (1999). A measure of subjective happiness: preliminary reliability and construct validation. Soc. Indic. Res. 46, 137-155.

Lyubomirsky, S., Sheldon, K. M., and Schkade, D. (2005). Pursuing happiness: the architecture of sustainable change. Rev. Gen. Psychol. 9 , 111-131.

Miller, T. Q., Smith, T. W., Turner, C. W., Guijarro, M. L., and Hallet, A. J. (1996). A meta-analytic review of research on hostility and physical health. Psychol. Bulletin 119, 322348.

Peterson, C., and Seligman, M. E. P. (2004). Character Strengths and Virtues: A Handbook and Classifcation. Washington, DC: American Psychological Association.

Rutter, M. (1985). Resilience in the face of adversity. Protective factors and resistance to psychiatric disorder. $\mathrm{Br}$. J. Psychiatry 147, 598-611.

Ryan, R. M., and Deci, E. L. (2001). “On happiness and human potentials: a review of research on hedonic and eudaimonic well-being," in Annual Review of Psychology, ed. S. Fiske (Palo Alto, CA: Annual Reviews, Inc.), 141-166.

Ryff, C. D., Love, G., Urry, H. L., Muller, D., Rosenkranz, M. A., Friedman, E. M., and Singer, B. (2006). Psychological well-being and ill-being: do they have distinct or mirrored biological correlates? Psychother. Psychosom. 75, 85-95.

Scheier, M. F., and Carver, C. S. (1985). Optimism, coping and health: assessment and implications of generalized outcome expectancies. Health Psychol.4, 219-247.
Scheier, M. F., Carver, C. S., and Brodges, M. W. (1994). Distinguish optimism from neuroticism, trait anxiety, self-mastery and self-esteem. A reevaluation of the life orientation test. J. Pers. Soc. Psychol. 67, 1063-1078.

Schwartz, S. H. (1992). "Universals in the content and structure of values: theory and empirical tests in 20 countries," in Advances in Experimental Social Psychology, Vol. 25, ed. M. Zanna (New York: Academic Press), 1-65.

Schwartz, S. H. (2003). A Proposal for Measuring Value Orientations Across Nations. Chapter 7 in the ESS Questionnaire Development Report. Available at: http:// www.europeansocialsurvey.org

Sears, D. O. (1986). College sophomores in the laboratory: influences of a narrow data base on social psychology's view of human nature. J. Pers. Soc. Psychol. 51, 515-530.

Seligman, M. E. P. (1991). Learned Optimism. New York: Knopf.

Seligman, M. E. P., and Csikszentmihalyi, M. (2000). Positive psychology: an introduction. Am. Psychol. 55, 5-14.

Seligman, M. E. P., Steen, T. A., Park, N., and Peterson, C. (2005). Positive psychology progress: empirical validation of interventions. Am. Psychol. 60, 410-421.

Sheldon, K. M., Abad, N., Ferguson, Y., Gunz, A., Houser-Marko, L., Nichols, C. P., and Lyubomirsky, S. (2010). Persistent pursuit of needsatisfying goals leads to increased happiness: a 6-month experimental longitudinal study. Motiv. Emotion $34,39-48$.

Steger, M. F., Frazier, P., Oishi, S., and Kaler, M. (2006). The Meaning in Life Questionnaire: assessing the presence of and search for meaning in life. J. Couns. Psychol. 53, 80-93.

Steger, M. F., Kashdan, T. B., and Oishi, S. (2008). Being good by doing good: eudaimonic activity and daily well-being correlates, mediators, and temporal relations. J. Res. Pers. 42, 22-42.

Steptoe, A., and Wardle, J. (2005). Positive affect and biological function in everyday life. Neurobiol. Aging 26, 108-112. 
Steptoe, A., Wardle, J., and Marmot, M. (2005). Positive affect and health-related neuroendocrine, cardiovascular, and inflammatory processes. Proc. Natl. Acad. Sci. U.S.A. 102, 6508-6512.

Tellegen, A. (1982). Multidimensional Personality Questionnaire Manual. Minneapolis, MN: University of Minnesota Press.

Trapnell, P. D., and Campbell, J. D. (1999). Private self-consciousness and the five-factor model of personality: distinguishing rumination from reflection. J. Pers. Soc. Psychol. 76, 284-304.
Veenhoven, R. (1997). Advances in understanding happiness. Rev. Québécoise Psychol. 18, 29-74.

Wallace, B. A., and Shapiro, S. L. (2006). Mental balance and wellbeing: building bridges between Buddhism and Western psychology. Am. Psychol. 61, 690-701.

Watson, D., Clark, L. A., and Tellegen, A. (1988). Development of a brief measure of positive and negative affect: the PANAS Scales. J. Pers. Soc. Psychol. 54, 1063-1070.

Werner, E. E. (1992). The children of Kauai: resiliency and recovery in adolescence and adulthood. J. Adolesc. Health 13, 262-268.
Conflict of Interest Statement: Conflict of Interest Statement: The authors declare that the research was conducted in the absence of any commercial or financial relationships that could be construed as a potential conflict of interest.

Received: 17 May 2011; accepted: 13 January 2012; published online: 07 February 2012.

Citation: Dambrun $M$, Ricard $M$, Després G, Drelon E, Gibelin E, Gibelin $M$, Loubeyre M, Py D, Delpy A, Garibbo $C$, Bray E, Lac $G$ and Michaux $O$ (2012) Measuring happiness: from fluctuating happiness to authenticdurable happiness. Front. Psychology 3:16. doi: 10.3389/fpsyg.2012.00016

This article was submitted to Frontiers in Personality Science and Individual Differences, a specialty of Frontiers in Psychology.

Copyright (C) 2012 Dambrun, Ricard, Després, Drelon, Gibelin, Gibelin, Loubeyre, Py, Delpy, Garibbo, Bray, Lac and Michaux. This is an open-access article distributed under the terms of the Creative Commons Attribution Non Commercial License, which permits noncommercial use, distribution, and reproduction in other forums, provided the original authors and source are credited. 